\title{
Respiração basal e relação de estratificação em solo cultivado com citros e tratado com resíduos orgânicos no estado de Sergipe
}

\section{Basal respiration and stratification ratio in soil cultivated with citrus and treated with organic residues in the state of Sergipe}

\author{
Juliana Augusta Moura ${ }^{1 *}$; Maria Isidória Silva Gonzaga²; \\ Joézio Luiz dos Anjos ${ }^{3}$; Anne Caroline Pina Rodrigues ${ }^{4}$; \\ Thamyres Dias da Silva Leão ${ }^{4}$; Lucia Catherinne Oliveira Santos ${ }^{4}$
}

\section{Resumo}

\begin{abstract}
A utilização de resíduos orgânicos no solo para melhorar sua qualidade, fornecer nutrientes as plantas e aumentar o estoque de carbono é uma prática antiga, mas pouco é conhecido sobre a aplicação de compostagem laminar em pomares de citros. O objetivo do presente trabalho foi avaliar a atividade microbiana, através da respiração basal, e as diferentes taxas de estratificação de algumas variáveis relacionadas a esse atributo, em um Argissolo Vermelho Amarelo tratado com resíduos orgânicos e cultivado com citros, no estado de Sergipe. Foram coletadas amostras de solo em três profundidades (0-5, 5-10 e 10-15 cm) em área cultivada com laranja pêra (Citrus sinensis, L. Osbeck) sob diferentes tratamentos 1.Compostagem laminar (aplicação, na projeção da copa, na zona de coroamento da planta, de camadas alternadas de resíduos orgânicos frescos e esterco ovino) 2. Compostagem laminar + NPK (o mesmo descrito no item 1 + adubação NPK recomendada pela análise do solo); 3. Húmus (aplicação, na projeção da copa, de composto organico humificado); 4. Húmus + NPK (o mesmo descrito no item 3 + NPK; 5. Controle + NPK (manejo convencional, onde a projeção da copa é mantida livre de plantas invasoras através de capina manual; com aplicação de fertilizantes aplicado na projeção da copa); 6 . Controle sem NPK (o mesmo descrito no item 5, sem aplicação de fertilizantes). O estudo foi realizado com três repetições. Verificou-se que a adição em superfície de resíduos orgânicos ao solo na zona de coroamento da laranjeira provocou um aumento das taxas de respiração microbiana, um acréscimo nos teores totais de matéria orgânica, assim como, a elevação de alguns atributos químicos como pH, $\mathrm{P}, \mathrm{Ca}$ e $\mathrm{Mg}$ no solo quando comparados ao solo sob citrus conduzido em manejo convencional. A relação de estratificação mostrou-se eficaz ao avaliar a influência das diferentes práticas de manejo entre as profundidades evidenciando a melhoria da atividade microbiana pelas práticas conservacionistas e indicando os tratamentos Húmus, Húmus + NPK e Compostagem laminar + NPK como os mais eficazes em aumentar os teores de matéria orgânica no solo.
\end{abstract}

Palavras-chave: Respiração basal, compostagem laminar, matéria orgânica

\footnotetext{
Abstract

The use of organic residues in the soil to improve its quality, provide nutrients to plant growth and increase carbon storage is an ancient practice, but little is known about the application of laminar

1 Parte da tese de mestrado da primeira autora apresentada a Universidade Federal de Sergipe, UFS, São Cristovão, SE. E-mail: juliana.augustamoura@gmail.com

2 Eng ${ }^{\mathrm{a}} \mathrm{Agr}^{\mathrm{a}}$, Prof $^{\mathrm{a}} \mathrm{Dr}^{\mathrm{a}}$ Adjunta do Dept ${ }^{\mathrm{o}}$ de Engenharia Agronômica, UFS, São Cristovão, SE. E-mail: mariaisisilva@gmail.com

3 Eng ${ }^{\circ}$ Agr $^{\circ}$, Dr. em Agronomia, Pesquisador da EMBRAPA, Aracaju, SE. E-mail: joezio.anjos@embrapa.br

4 Discentes do curso de graduação em Engenharia Florestal, UFS, São Cristovão, SE. E-mail: carolpina008@gmail.com; thamyrex@hotmail.com; ktherinne_love@hotmail.com

* Autor para correspondência
} 
composting in citrus orchards. The objective of this study was to evaluate the microbial activity through microbial respiration, and the different rates stratification of some variables related to this attribute of an Ultisol cultivated with citrus and treated with organic waste in the state of Sergipe. Soil samples were collected in the layers $0-5 \mathrm{~cm}, 5-10 \mathrm{~cm}$, and 10-15 cm in a citrus orchard (Citrus sinensis, L. Osbeck) under different treatments 1 . Layering organic residue (crop wastes placed in layers under the plant canopy) 2. Layering organic residue + NPK (the same as described in iten $1+$ NPK); 3. Humus (Humified organic compost applied under the plant canopy); 4. Humus + NPK (the same as described in iten 3 + NPK); 5. Control + NPK (plant canopy was kept free of residues, + NPK application); 6. Control - NPK (plant canopy was kept free of residues, without application of NPK), with three replications. It has been found that the use of the organic residue in the plant canopy increased microbial respiration rate and total organic matter content, as well as an increase in some chemical attributes as $\mathrm{pH}, \mathrm{P}, \mathrm{Ca}$ and $\mathrm{Mg}$ in all treatments compared the control. The ratio stratification was effective to evaluate the influence of different management practices between depths demonstrating an improvement in microbial activity by more practical conservation treatments and indicating that the use of Humus, humus + NPK and alternate layering residues + NPK were the most effective in increasing the organic matter content in the soil.

Key words: Basal respiration, alternate layering residues, organic matter

\section{Introdução}

A respiração do solo ou respiração basal descreve o nível da atividade microbiana, permite fazer inferências sobre o teor e a decomposição da matéria orgânica além de refletir a capacidade de sustentação da vida no solo, através da atividade de plantas, animais e microrganismos. É um dos parâmetros mais antigos utilizados para quantificar a atividade microbiana, um processo altamente influenciado pelo tipo de vegetação, sobretudo pelas mudanças impostas no microclima local e na quantidade de serrapilheira. Assim como outros processos metabólicos, a respiração é dependente do estado fisiológico da célula microbiana e é influenciada por diversos fatores do solo, como: umidade, temperatura, estrutura, disponibilidade de nutrientes, textura, relação $\mathrm{C} / \mathrm{N}$, presença de resíduos orgânicos, entre outros (TANG et al., 2006; SILVA et al., 2010).

Durante a decomposição de substratos orgânicos, os microrganismos contribuem para a ciclagem de nutrientes no solo (SHARMA et al., 2013), mas produzem dióxido de carbono $\left(\mathrm{CO}_{2}\right)$, que é emitido para a atmosfera (CURIEL YUSTE et al., 2007; LAL, 2010). Portanto, a respiração basal, além de indicar funções importantes do solo, também desempenha um papel crucial no ciclo global do carbono, pois o solo contém duas vezes mais carbono do que a atmosfera (COLEMAN et al., 2002), com emissões em torno de 68 a 100 Pg $\mathrm{C} /$ ano. Numa escala global, a emissão de $\mathrm{CO}_{2}$ do solo é 10 vezes maior do que a dos combustíveis fósseis em áreas submetidas ao desmatamento (BREVIK, 2012). Por essa razão, a respiração do solo tem sido foco de muitos estudos nos diversos centros de pesquisa no mundo (BORKEN; MUHS; BEESE, 2002; ZIMMERMANN; FREY, 2002; YI et al., 2007; ANANYEVA et al., 2008; DING et al., 2010; KOERBER et al., 2010).

As práticas agrícolas modernas visam maior eficiência de produtividade e a conservação dos recursos ambientais. A adoção de sistemas de manejo conservacionistas que priorizam a manutenção de resíduos de culturas sobre a superfície do solo, minimizando as perturbações em seus atributos, é uma prática cada vez mais comum devidoao crescente interesse pela agricultura sustentável (CHENEBY et al., 2010), pois representa uma importante fonte de carbono que ajuda no restabelecimento da matéria orgânica decomposta como resultado das atividades de cultivo. Sabe-se que a conversão de áreas nativas em áreas cultivadas resulta em perdas de carbono em torno de 20 a $40 \%$, e essas perdas continuam durante o processo produtivo, principalmente em áreas de culturas anuais (BREVIK, 2013). 
Além dos resíduos culturais, a necessidade de preservar o meio ambiente, através do descarte adequado e da reutilização, tem estimulado o aproveitamento dos mais variados tipos de resíduos orgânicos que são gerados em atividades rurais, agroindustriais e urbanas, seja como fertilizantes ou como condicionadores de solo (TEDESCO et al., 1999).

Os benefícios do reaproveitamento dos resíduos orgânicos nas propriedades do solo e na produção vegetal já foram comprovados em diversos experimentos. Rodda et al. (2006) verificaram que os humatos produzidos a partir de esterco bovino e da mistura esterco bovino associado ao bagaço de cana-de-açúcar proporcionaram estímulos significativos no crescimento radicular das plantas de alface. Trannin, Siqueira e Moreira (2007), ao cultivarem milho com doses crescentes de biossólido, observaram alterações na matéria orgânica e melhoria na maioria das características biológicas relacionadas à fertilidade do solo. Brito et al. (2008) constataram que os compostos da fração sólida do chorume podem ser utilizados como corretivos orgânicos do solo, com benefícios agronômicos e ambientais.

No entanto, a aplicação de variados tipos de resíduos no solo, em diferentes quantidades, altera o comportamento da microbiota, podendo estimular ou inibir a sua atividade, principalmente em relação aos processos de transformação da matéria orgânica eà ciclagem de nutrientes eàs interações de troca com a maioria das espécies de plantas, especialmente as de importância agrícola (ZATORRE, 2008). Chaves et al. (2006), ao avaliarem os impactos da aplicação de diferentes concentrações de lodo da indústria têxtil na atividade microbiana, verificaram que a respiração basal do solo aumentou nos três solos estudados. Kummer et al. (2008), ao estudarem a influência de quatro sistemas de uso do solo sobre a biota, constataram uma elevação da respiração basal do solo devido a adição de resíduos de canade-açúcar e milho, sendo o aumento obtido pelos resíduos de milho mais expressivos.
Em sistemas de plantio direto, cultivos perenes e área de vegetação nativa, onde não há revolvimento da camada arável do solo, a deposição de resíduos ocorre na superfície e em função disso, muitos atributos do solo são submetidos à estratificação em profundidade, com maior acúmulo na camada superficial (FRANZLUEBBERS; SCHOEMBERG; ENDALE, 2007), melhorando a qualidade do solo através da maior formação de agregados e aeração (SÁ; LAL, 2009), o que influencia significativamente a atividade microbiana. O objetivo do presente trabalho foi avaliar a atividade microbiana, através da respiração basal e as taxas de estratificação em solo tratado com resíduos orgânicos e cultivado com citros, no estado de Sergipe. Até o presente, virtualmente nenhum trabalho foi publicado a respeito do uso de compostagem laminar em cultura de citros.

\section{Materiais e Métodos}

O experimento foi instalado em abril de 2010, em um pomar de laranja pêra (Citrus sinensis, L. Osbeck) implantado há 5 anos, no assentamento Mangabeiras, situado no município de Umbaúba, localizado na região centro sul do estado de Sergipe, cujas coordenadas geográficas são $11^{\circ} 22^{\prime}$ 32 " S de latitude e $37^{\circ} 39^{\prime} 35^{\prime \prime} \mathrm{W}$ de longitude. A Precipitação média anual é em torno de $1.601 \mathrm{~mm}$ com temperatura média anual de $24,3{ }^{\circ} \mathrm{C}$. O relevo se apresenta como plano a suave ondulado; o solo é caracterizado como Argissolo Vermelho Amarelo, com textura arenosa. Em sua grande maioria, esse solo está localizado em região de Tabuleiros Costeiros, cujos solos apresentam camada coesa que dificulta a penetração das raízes e a adequada distribuição da água ao longo do perfil. Além da baixa capacidade de retenção de água, esses solos são muito pobres em matéria orgânica (CINTRA; PORTELA; NOGUEIRA, 2004; EMDAGRO, 2008). O espaçamento da cultura foi de $6 \mathrm{~m} \mathrm{x} 4 \mathrm{~m}$ (416 plantas ha-1). 
Foi utilizado o delineamento em blocos casualizados, com sete tratamentos: 1.Compostagem laminar (aplicação, na projeção da copa, na zona de coroamento da planta, de camadas alternadas de palha triturada de coqueiro, capim elefante, gliricídia e a parte aérea da folha picada do milho, esterco ovino e fosfato de Gafsa, até uma altura aproximada de $20 \mathrm{~cm}$, com base nas orientações de Nunes e Santos (2009)); 2. Compostagem laminar + NPK (o mesmo descrito no item 1 + adubação NPK recomendada pela análise do solo); 3. Húmus (aplicação, na projeção da copa, na zona de coroamento da planta, de composto preparado na propriedade agrícola utilizando restos culturais de capim elefante (Penisetum purpureum) e gliricia (Gliricia sepium), e esterco ovino); 4. Húmus + NPK (o mesmo descrito no item $3+\mathrm{NPK}$; 5. Controle + NPK (manejo convencional, onde a projeção da copa é mantida livre de plantas invasoras através de capina manual; com aplicação de fertilizantes na projeção da copa); 6. Controle sem NPK (manejo convencional, onde a projeção da copa é mantida livre de plantas invasoras através de capina manual; sem aplicação de fertilizantes). O estudo foi realizado com três repetições. Cada tratamento foi aplicado em duas plantas de cada bloco. De um tratamento para o outro, uma planta não recebeu tratamento (Figura 1).

Figura 1. Croqui da área experimental. Assentamento Mangabeiras, Umbaúba-SE.

\begin{tabular}{|c|c|c|c|c|c|c|c|c|c|c|c|c|c|c|c|c|c|c|}
\hline 0 & 0 & 0 & 0 & 0 & 0 & 0 & 0 & 0 & 0 & 0 & 0 & 0 & 0 & 0 & 0 & 0 & 0 & 0 \\
\hline 0 & 1 & 1 & 0 & 6 & 6 & 0 & 2 & 2 & $\mathrm{O}$ & 3 & 3 & 0 & 4 & 4 & $\mathrm{O}$ & 5 & 5 & 0 \\
\hline 0 & 0 & 0 & 0 & 0 & 0 & 0 & 0 & 0 & 0 & 0 & 0 & 0 & 0 & 0 & 0 & 0 & 0 & 0 \\
\hline 0 & 5 & 5 & 0 & 1 & 1 & 0 & 4 & 4 & 0 & 6 & 6 & 0 & 2 & $?$ & 0 & 3 & 3 & 0 \\
\hline 0 & 0 & 0 & 0 & 0 & 0 & 0 & 0 & 0 & 0 & 0 & 0 & 0 & 0 & 0 & 0 & 0 & 0 & 0 \\
\hline 0 & 6 & 6 & 0 & 2 & 2 & 0 & 5 & 5 & 0 & 3 & 3 & 0 & 4 & 4 & 0 & 1 & 1 & 0 \\
\hline 0 & 0 & 0 & 0 & 0 & 0 & 0 & 0 & 0 & 0 & 0 & 0 & 0 & 0 & 0 & 0 & 0 & 0 & 0 \\
\hline
\end{tabular}

* $\mathrm{O}=$ planta; $1,2,3,4,5,6=$ tratamentos. Espaçamento: 6 × 4 m.

1. Croqui da área experimental. Assentamento Mangabeiras, Umbaúba-SE.

Fonte: Elaboração dos autores.

Nos tratamentos 1 e 2 , foram aplicados, por planta no primeiro ano, $50 \mathrm{~L}$ de esterco de ovino $+300 \mathrm{~g}$ de fosfato de Gafsa $+150 \mathrm{~L}$ de palha de coqueiro triturada associada a palha de capim elefante e gliricídia $+50 \mathrm{~L}$ de esterco de ovino $+300 \mathrm{~g}$ de fosfato de Gafsa $+200 \mathrm{~L}$ de folha picada da parte aérea do milho associados a palha de capim elefante e gliricídia. E no segundo ano, $50 \mathrm{~L}$ de esterco de ovino $+100 \mathrm{~L}$ de palha de coco triturada associados a palha de capim elefante e gliricídia +50 L de esterco de ovino $+50 \mathrm{~L}$ de palha de coco triturada associada a palha de capim elefante e gliricídia +
1200 g de fosfato de Gafsa. Nos tratamentos 3 e 4, foram aplicados $100 \mathrm{~L}$ de composto humificado nos dois anos; e nos tratamentos 2, 4 e 5, foram utilizados 500 g por planta do NPK 10-20-20 granulado, aplicados em faixas ao redor da planta, numa faixa que inicia-se a $0,20 \mathrm{~m}$ do tronco e termina a $1,8 \mathrm{~m}$ do mesmo, em seguida foram aplicados os demais componentes dos tratamentos.

As amostras de solo foram coletadas dois anos após a instalação do experimento. Antes da coleta, os resíduos visualmente não decompostos foram removidos da superficie do solo, em cada ponto de 
amostragem. As amostras deformadas de solo foram coletadas com o auxílio de um trado holandês, em junho de 2012, em três profundidades (0-5, 5-10 e 10-15 cm). Três amostras simples coletadas em cada profundidade na projeção da copa de cada planta foram combinadas para produzir uma amostra composta, sendo três amostras compostas por profundidade, por planta. As amostras de solo utilizadas para determinação da respiração basal foram aramazenadas sob refrigeração a $4^{\circ}$ $\mathrm{C}$, e as análises foram realizadas uma semana após a coleta. As amostras de solo destinadas às análises químicas e físicas foram secas à sombra e a temperatura ambiente, destorroadas e passadas em peneiras de malha $2 \mathrm{~mm}$ e armazenadas em sacos plásticos. As amostras indeformadas de solo foram coletadas nos mesmos pontos de coleta das amostras deformadas, com amostrador de Uhland, em cilindros volumétricos de $5,2 \mathrm{~cm}$ de diâmetro, altura de $2 \mathrm{~cm}$ e $42,47 \mathrm{~cm}^{3}$ de volume, seguindo a metodologia descrita pela Embrapa (1997), para determinação da densidade do solo.

As amostras foram analisadas no laboratório de água e solo da Universidade Federal de Sergipe. A respiração basal foi determinada seguindo a metodologia descrita por Alef e Nannipieri (1995), cujo princípio do método consiste na captura de $\mathrm{CO}_{2}$ liberado da respiração microbiana pela solução de $\mathrm{NaOH}$ e formação de $\mathrm{Na}_{2} \mathrm{CO}_{3}$. Inicialmente foram pesadas $25 \mathrm{~g}$ de cada amostra de solo em recipientes plásticos previamente identificados. Essas amostras foram umedecidas à $70 \%$ da capacidade de campo e colocadas dentro de um pote de vidro juntamente com um Becker de $50 \mathrm{ml}$ contendo $10 \mathrm{ml}$ de $\mathrm{NaOH}$ 0,5 M, sendo tampados imediatamente. Após $72 \mathrm{~h}$ de incubação, com temperatura controlada de 26 ${ }^{\circ} \mathrm{C}$, os béqueres foram retirados do pote de vidro, sendo adicionado $1 \mathrm{ml}$ de $\mathrm{BaCl}_{2}$ e duas gotas de fenolftaleína para titulação. A mistura foi titulada com $\mathrm{HCl}$ 0,5 $\mathrm{M}$ até o ponto de viragem (mudança da cor branca para cor rósea), anotando-se o volume gasto. $\mathrm{O}$ mesmo procedimento foi realizado na prova em branco. Para realização dos cálculos foram pesados amostras de $1 \mathrm{~g}$ de solo umedecido, após o tempo de incubação, e colocados em estufa a $105^{\circ} \mathrm{C}$ por $24 \mathrm{~h}$, sendo pesados novamente para a obtenção do peso seco.

O cálculo para determinação da RBS é dado pela seguinte equação:

RBS (mg de C-CO $\mathrm{kg}^{-1}$ solo hora $\left.{ }^{-1}\right)=(((\mathrm{Vb}-$ Va ) . M . 6 . 1000)/ Ps) / T

Onde: RBS - carbono oriundo da respiração basal do solo; $\mathrm{Vb}(\mathrm{ml})$ - volume de ácido clorídrico gasto na titulação da solução controle (branco); Va (ml) - volume gasto na titulação da amostra; M molaridade exata do $\mathrm{HCl}$; Ps (g) - massa de solo seco; e T - tempo de incubação da amostra em horas.

Para a determinação do teor total da matéria orgânica do solo foi utilizado o método volumétrico, com titulação do excesso de dicromato de potássio pelo sulfato ferroso amoniacal, conforme descrito em Yeomans e Bremner (1988), adaptado por Mendonça e Matos (2005).

A taxa de estratificação foi calculada conforme Franzluebbers (2002). Em cada ponto amostrado, o valor da camada superficial do solo $(0-5 \mathrm{~cm})$ foi dividido pelo valor da camada subsuperficial (5-10 $\mathrm{cm})$ e também pela camada mais profunda (10-15 $\mathrm{cm})$. Foram calculadas taxas de estratificação para a atividade microbiana, matéria orgânica total do solo e fósforo.

Os resultados de respiração basal e matéria orgânica total foram submetidos à análise de variância e as médias foram comparadas pelo teste de Scott-Knott a $5 \%$ de probabilidade por meio do software SISVAR ${ }^{\circledR}$ (FERREIRA, 2003).

\section{Resultados e Discussão}

A atividade microbiana, quantificada através da respiração basal do solo (RBS), resultou em valores que variaram entre 30,0 a $65,0 \mathrm{mg} \mathrm{CO}_{2}$ $\mathrm{kg}^{-1}(0-5 \mathrm{~cm})$, de 23,0 a $47,3 \mathrm{mg} \mathrm{CO} \mathrm{kg}^{-1}(5-$ $10 \mathrm{~cm})$ e de 19,9 a $55,2 \mathrm{mg} \mathrm{CO} \mathrm{kg}^{-1}(10-15 \mathrm{~cm})$, 
sendo o menor valor observado para o tratamento Húmus na camada de $10-15 \mathrm{~cm}$ e os maiores para os tratamentos Compostagem laminar e Húmus, ambos com adição de NPK, na camada de 0-5 cm (Figura 2). A aplicação de resíduos orgânicos, no intuito de melhorar a qualidade do solo antes usado em manejo convencional de citros, promoveu aumentos de $60 \%, 80 \%$ e $110 \%$ na atividade microbiana nos tratamentos Compostagem laminar, Compostagem laminar + NPK e Húmus + NPK, respectivamente (Figura 2). De acordo com os valores observados para a respiração basal na Figura 2, a adição de fertilizantes nos tratamentos com resíduos orgânicos estimulou igualmente a maior atividade biológica e decomposição dos compostos orgânicos presentes, principalmente na camada de 0-5 cm do solo. Esse resultado confirma a importância do nível nutricional da célula microbiana durante o preocesso de mineralização de compostos orgânicos (VIEIRA; CASTILHOS; CASTILHOS, 2011). A maior liberação de $\mathrm{CO}_{2}$ geralmente ocorre em função da maior atividade biológica que se encontra relacionada diretamente com a quantidade de carbono lábil existente no solo (MAZURANA et al., 2013). Os principais fatores que influenciam a atividade microbiana são a composição dos resíduos adicionados, seu estado físico e sua forma de aplicação (POWLSON, 2001). Além disso, a alta mineralização observada nos tratamentos Compostagem laminar + NPK e Húmus + NPK está relacionado à natureza da fonte de N aplicada nesses tratamentos, a uréia, que por meio da urease, é rapidamente transformada para a forma amoniacal.

Figura 2. Médias da respiração basal do solo $\left(\mathrm{mg} \mathrm{CO}_{2} \mathrm{~kg}^{-1}\right)$ sob diferentes tratamentos, nas profundidades de $0-5 \mathrm{~cm}$, 5-10 cm, e 10-15 cm, em área de citros no estado de Sergipe.

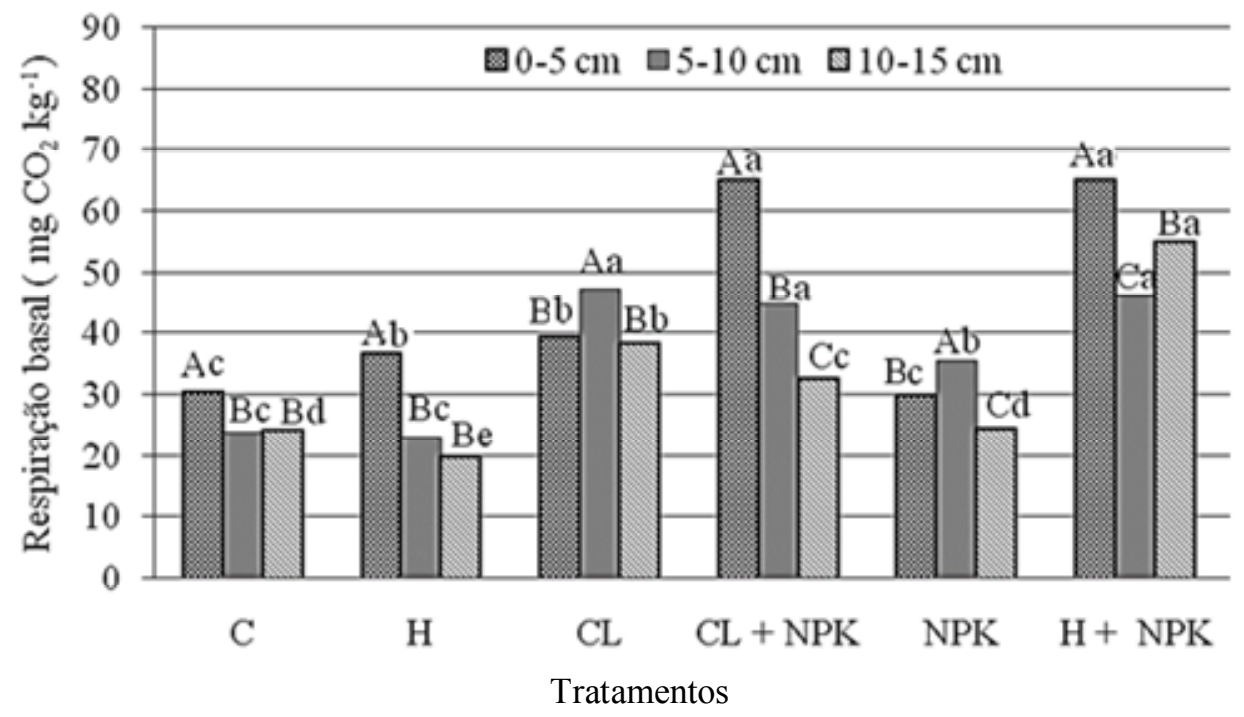

\footnotetext{
* Médias seguidas das mesmas letras minúsculas na mesma profundidade e em tratamentos diferentes não diferem entre si pelo teste de Scott-Knott em 5\% de probabilidade; ** Médias seguidas das mesmas letras maiúsculas em profundidades diferentes e no mesmo tratamento, não diferem entre si pelo teste Scott-Knott a 5\% de probabilidade.

C - Controle sem NPK (projeção da copa mantida livre de plantas invasoras através de capina manual; sem aplicação de fertilizantes); $\mathrm{H}$ - Húmus (composto preparado na propriedade agrícola utilizando restos culturais e estercos); $\mathrm{CL}-\mathrm{Compostagem}$ laminar (resíduos culturais de palha triturada de coqueiro, capim elefante variedade napier, gliricídia e a parte aérea da folha picada do milho dispostos na projeção da copa, em lâminas alternadas com esterco ovino e fosfato de Gafsa até uma altura aproximada de $20 \mathrm{~cm}$ ); CL + NPK - Compostagem laminar + NPK (adubação recomendada pela análise do solo); NPK: Controle com aplicação de NPK; H + NPK - Húmus + NPK.

2. Médias da respiração basal do solo $\left(\mathrm{mg} \mathrm{CO}_{2} \mathrm{~kg}^{-1}\right)$ sob diferentes tratamentos, nas profundidades de $0-5 \mathrm{~cm}, 5-10 \mathrm{~cm}$, e $10-15$ $\mathrm{cm}$, em área de citros no estado de Sergipe.

Fonte: Elaboração dos autores.
} 
Altos valores de respiração basal podem indicar, em curto prazo, a maior liberação de nutrientes para as plantas, e em curto ou longo prazo, a perda de carbono orgânico do solo para a atmosfera (PARKIN; DORAN; FRANCOP-VIZCAÍNO, 1996). No entanto, é desejável que a intensidade deste processo seja coordenada com as necessidades fisiológicas das plantas, o que diminuiria as perdas no solo.

Levando-se em consideração as diferentes profundidades avaliadas, de forma geral, a aplicação de resíduos orgânicos, associados ou não a adubação mineral, na zona de coroamento da laranjeira, promoveu aumentos de 23 a $116 \%$ nas taxas de respiração microbiana, na profundidade de 0-5 $\mathrm{cm}$, em relação ao tratamento controle. As maiores diferenças entre os tratamentos foram observadas na camada superficial do solo, onde normalmente há maior aporte de resíduos (Figura 2).

$\mathrm{Na}$ camada de $5-10 \mathrm{~cm}$, as maiores taxas de RBS foram verificadas nos tratamentos Compostagem laminar, Compostagem laminar + NPK e Húmus + NPK (Figura 2), e não houve diferença significativa entre esses tratamentos. Esse resultado deve-se à maior proximidade da camada $0-5 \mathrm{~cm}$, onde houve maior contribuição na adição de resíduos orgânicos, o que proporcionou maior quantidade de matéria orgânica com grandes quantidades de carbono prontamente disponível (FRANZLUEBBERS, 2002; SÁ; LAL, 2009). Ainda na camada de 5-10 cm, as menores taxas de liberação de $\mathrm{CO}_{2}$ foram observadas no tratamento Controle e no tratamento Húmus. No tratamento controle, esse resultado é explicado pela reduzida quantidade de matéria orgânica, a qual é proveniente apenas da decomposição de folhas da laranjeira que caem no chão durante o processo natural de crescimento, cuja contribuição acontece preferencialmente na camada de $0-5 \mathrm{~cm}$. Já com relação ao tratamento Húmus, pelo fato de se tratar de um composto energeticamente estável, a sua adição não resultou em estímulo significativo da atividade microbiana, principalmente pela reduzida quantidade de carbono lábil. A presença de húmus, no entanto, continua sendo benéfica ao solo por melhorar sua estrutura e manter elevados níveis de carbono.

Na camada de 10-15 cm, o maior valor de RBS ficou por conta do tratamento Húmus + NPK e o menor pelo tratamento Húmus (Figura 2). O Húmus é o tratamento que apresenta matéria orgânica na forma mais estável em relação aos demais, porém quando associado a fertilizantes minerais, que são ricos em nutrientes mais prontamente disponíveis, estimulou a biota aumentando assim a taxa de respiração basal no solo, cujo efeito se estendeu até a maior profundidade avaliada.

Ao avaliar os mesmos tratamentos em profundidades diferentes, foi verificada uma redução significativa na liberação de $\mathrm{CO}_{2}$, a exceção dos tratamentos Compostagem laminar e Controle + NPK, que tiveram um aumento das taxas de RBS na camada intermediária $(5-10 \mathrm{~cm})$ (Figura 2). A atividade microbiana tende a ser maior nas camadas mais superficiais devido à maior quantidade de matéria orgânica decomposta pela biota do solo (PRAGANA et al., 2012), e diminui em profundidade acompanhando a redução da matéria orgânica (Figura 3) bem como outros indicadores biológicos (ARAÚJO; MONTEIRO, 2007). 
Figura 3. Médias da matéria orgânica total $\left(\mathrm{g} \mathrm{kg}^{-1}\right)$ nas três profundidades em solos sob diferentes tratamentos em área de citros no estado de Sergipe.

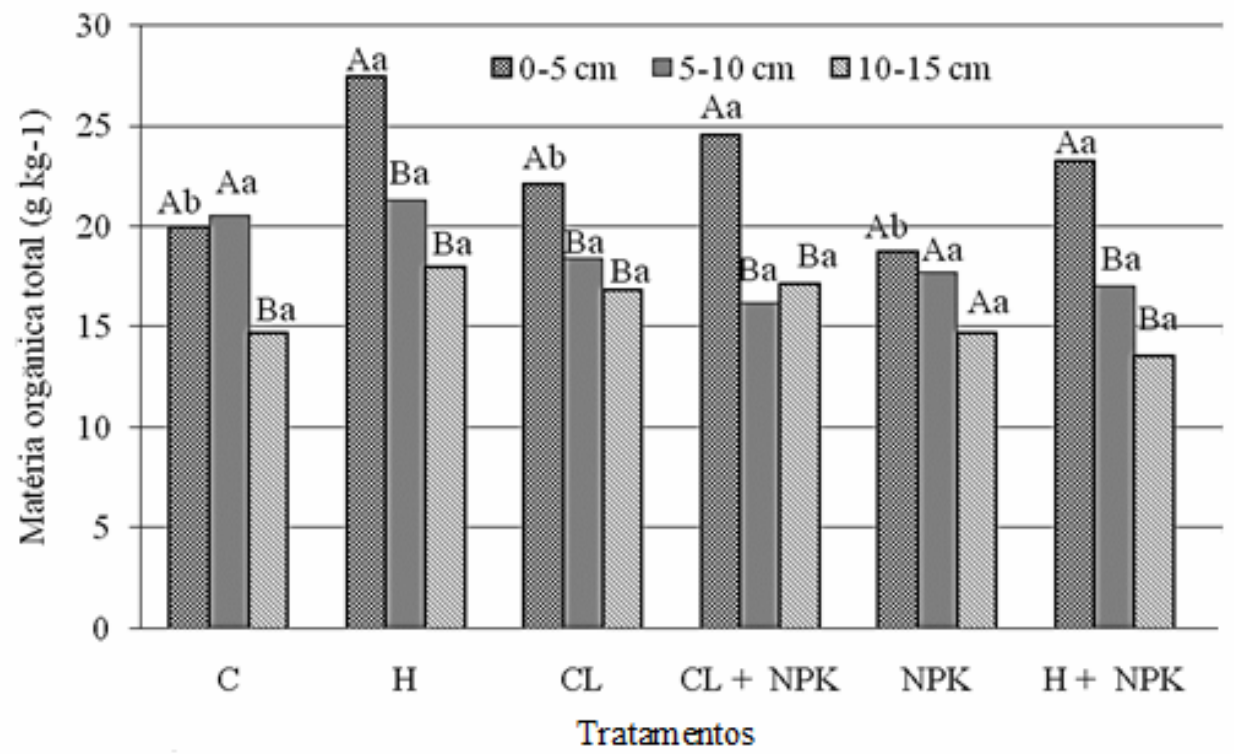

\begin{abstract}
* Médias seguidas das mesmas letras minúsculas na mesma profundidade e em tratamentos diferentes não diferem entre si pelo teste de Scott-Knott em 5\% de probabilidade; ** Médias seguidas das mesmas letras maiúsculas em profundidades diferentes e no mesmo tratamento, não diferem entre si pelo teste Scott-Knott a 5\% de probabilidade.

C - Controle sem NPK (projeção da copa mantida livre de plantas invasoras através de capina manual; sem aplicação de fertilizantes); $\mathrm{H}$ - Húmus (composto preparado na propriedade agrícola utilizando restos culturais e estercos); CL - Compostagem laminar (resíduos culturais de palha triturada de coqueiro, capim elefante variedade napier, gliricídia e a parte aérea da folha picada do milho dispostos na projeção da copa, em lâminas alternadas com esterco ovino e fosfato de Gafsa até uma altura aproximada de $20 \mathrm{~cm}$ ); CL + NPK - Compostagem laminar + NPK (adubação recomendada pela análise do solo); NPK: Controle com aplicação de NPK; H + NPK - Húmus + NPK.

3. Médias da matéria orgânica total $\left(\mathrm{g} \mathrm{kg}^{-1}\right)$ nas três profundidades em solos sob diferentes tratamentos em área de citros no estado de Sergipe.
\end{abstract}

Fonte: Elaboração dos autores.

Sampaio, Araújo e Santos (2008), ao estudarem o impacto dos sistemas de cultivo convencional e orgânico de frutas sobre indicadores biológicos da qualidade do solo em um Neossolo Quartzarênico, do estado do Piauí, constataram que a adoção do sistema orgânico aumentou a atividade microbiana e o conteúdo de carbono orgânico do solo, mostrando benefícios para esse sistema agrícola. Silveira et al. (2011), ao avaliarem as mudanças microbiológicas ocorrentes em um Argissolo Vermelho Amarelo após a aplicação de dejeto suíno e calcário, verificaram que a liberação de $\mathrm{C}-\mathrm{CO}_{2}$ aumentou com a aplicação de até $24 \mathrm{Mg} \mathrm{ha}^{-1}$, sendo que o percentual de biodegradação do resíduo manteve-se praticamente inalterado até a dose de
$18 \mathrm{Mg} \mathrm{ha}^{-1}$ de dejeto suíno. Schmidt et al. (2013) também verificaram maior atividade microbiana nas áreas de produção orgânica do que nas áreas de produção convencional ao avaliarem sistemas de produção olerícola orgânica e convencional, no município de Novo Hamburgo, RS. Cancellier et al. (2011) observaram em estudo com diferentes doses de esterco bovino, aumentos significativos na altura de plantas final, massa verde e produtividade de grãos com as maiores doses de esterco. Modesto et al. (2009) verificaram o efeito da adição do lodo de esgoto e resíduos orgânicos sobre o crescimento de duas espécies arbóreas de Cerrado e constataram maior atividade microbiana e maior crescimento para as duas espécies arbóreas nos tratamentos com 
lodo de esgoto, melhorando também a fertilidade do solo, com aumento dos teores de P, MO, Ca e $\mathrm{Mg}$, sendo que a matéria orgânica e o $\mathrm{P}$ tiveram seus teores elevados nos tratamentos com mistura de lodo de esgoto e demais resíduos.

O aumento dos teores $\mathrm{P}, \mathrm{Ca}$ e $\mathrm{Mg}$ também foram verificados neste trabalho, assim como a elevação do $\mathrm{pH}$, em todos os tratamentos, nas três profundidades
(Tabela 1). Já o incremento de MO foi mais facilmente observado na camada superficial (Figura 3). De acordo com Pavinato e Rosolem (2008), a adição de resíduos vegetais resulta na elevação do pH por promover a complexação de $\mathrm{H}$ e $\mathrm{Al}$ com compostos do resíduo vegetal, deixando o $\mathrm{Ca}$ e o Mg mais livres na solução do solo (Tabela 1).

Tabela 1. Caracterização química e física do solo sob diferentes tratamentos, nas profundidades de 0-5 cm, 5-10 cm, e 10-15 cm, em área de citros no estado de Sergipe.

\begin{tabular}{|c|c|c|c|c|c|c|c|}
\hline \multirow[t]{2}{*}{ Tratamentos } & $\mathrm{pH}$ & $\mathrm{Ca}$ & $\mathrm{Mg}$ & $\mathrm{H}$ & $\mathrm{Al}$ & $\mathrm{P}$ & Ds \\
\hline & $\left(\mathrm{H}_{2} \mathrm{O}\right)$ & \multicolumn{4}{|c|}{------ $\left(\mathrm{cmol}_{\mathrm{c}} \mathrm{dm}^{-3}\right)------$} & $\left(\mathrm{mg} \mathrm{dm}^{-3}\right)$ & $\left(\mathrm{g} \mathrm{cm}^{-3}\right)$ \\
\hline \multicolumn{8}{|c|}{$0-5 \mathrm{~cm}$} \\
\hline Compostagem laminar & 7,55 & 3,63 & 3,31 & 1,32 & 0,00 & 176,9 & 1,29 \\
\hline Compostagem laminar + NPK & 7,54 & 3,76 & 3,49 & 0,99 & 0,00 & 508,8 & 1,23 \\
\hline Húmus & 7,39 & 4,92 & 2,70 & 0,83 & 0,00 & 569,5 & 1,24 \\
\hline Húmus + NPK & 6,76 & 4,45 & 2,71 & 1,24 & 0,00 & 446,5 & 1,39 \\
\hline Controle - NPK & 6,80 & 3,42 & 2,23 & 2,23 & 0,00 & 13,07 & 1,40 \\
\hline Controle + NPK & 6,23 & 2,86 & 1,75 & 1,98 & 0,00 & 77,01 & 1,39 \\
\hline \multicolumn{8}{|c|}{$5-10 \mathrm{~cm}$} \\
\hline Compostagem laminar & 7,00 & 3,25 & 2,07 & 1,27 & 0,05 & 96,50 & 1,44 \\
\hline Compostagem laminar + NPK & 7,00 & 3,04 & 2,63 & 0,78 & 0,05 & 90,39 & 1,24 \\
\hline Húmus & 7,10 & 3,29 & 2,32 & 0,83 & 0,00 & 105,1 & 1,56 \\
\hline Húmus + NPK & 6,74 & 3,61 & 2,15 & 0,91 & 0,00 & 90,98 & 1,50 \\
\hline Controle - NPK & 5,50 & 2,25 & 1,46 & 3,07 & 0,15 & 3,75 & 1,50 \\
\hline Controle + NPK & 6,95 & 2,11 & 1,50 & 2,13 & 0,10 & 31,51 & 1,50 \\
\hline \multicolumn{8}{|c|}{$10-15 \mathrm{~cm}$} \\
\hline Compostagem laminar & 6,95 & 2,40 & 1,37 & 1,32 & 0,00 & 83,90 & 1,22 \\
\hline Compostagem laminar + NPK & 6,97 & 2,52 & 1,61 & 2,43 & 0,05 & 38,86 & 1,26 \\
\hline Húmus & 6,95 & 3,67 & 2,05 & 0,83 & 0,00 & 75,04 & 1,59 \\
\hline Húmus + NPK & 6,70 & 2,82 & 1,65 & 1,52 & 0,05 & 25,14 & 1,44 \\
\hline Controle - NPK & 5,91 & 2,25 & 1,47 & 2,84 & 0,05 & 7,03 & 1,41 \\
\hline Controle + NPK & 5,86 & 2,35 & 1,31 & 2,10 & 0,05 & 13,53 & 1,43 \\
\hline
\end{tabular}

Descrição dos tratamentos avaliados: Compostagem laminar - resíduos culturais de palha triturada de coqueiro, capim elefante variedade napier, gliricídia e a parte aérea da folha picada do milho dispostos na projeção da copa, em lâminas alternadas com esterco ovino e fosfato de Gafsa até uma altura aproximada de $20 \mathrm{~cm}$; Húmus - composto preparado na propriedade agrícola utilizando restos culturais e estercos; Controle - projeção da copa mantida livre de plantas invasoras através de capina manual; sem aplicação de fertilizantes; NPK - adubação recomendada pela análise do solo.

4. Caracterização química e física do solo sob diferentes tratamentos, nas profundidades de 0-5 cm, 5-10 cm, e 10-15 cm, em área de citros no estado de Sergipe.

Fonte: Elaboração dos autores. 
A matéria orgânica do solo (MOS) apresentou valores que variaram de 18,8 a 27,5 $\mathrm{g} \mathrm{kg}^{-1}(0-5 \mathrm{~cm})$, de 16,2 a $21,3 \mathrm{~g} \mathrm{~kg}^{-1}(5-10 \mathrm{~cm})$ e de 13,6 a $18,9 \mathrm{~g}$ $\mathrm{kg}^{-1}(10-15 \mathrm{~cm})$, sendo o menor valor observado na camada de 10-15 cm para o tratamento Húmus + NPK e o maior na camada de $0-5 \mathrm{~cm}$ para o tratamento Húmus (Figura 3). Na profundidade de $0-5 \mathrm{~cm}$, verificou-se que os tratamentos que tiveram a adição de resíduos orgânicos foram os que apresentaram os maiores teores de MOS, a exceção do tratamento Compostagem laminar que apresentou valores semelhantes ao dos tratamentos que não receberam a incorporação de resíduos orgânicos (Controle sem e com NPK). Provavelmente, isso ocorreu em função do tratamento Compostagem laminar apresentar conteúdo orgânico mais facilmente decomponível, o que estimulou a atividade microbiana, causando a diminuição nos teores de matéria orgânica. Nas profundidades de $5-10 \mathrm{~cm}$ e de $10-15 \mathrm{~cm}$ não foram observadas diferenças significativas entre os tratamentos. No geral, o teor total da MOS foi maior na camada mais superficial $(0-5 \mathrm{~cm})$ apresentando um decréscimo significativo com o aumento da profundidade, exceto nos tratamentos Controle com e sem NPK (Figura 3).

Rocha, Gonçalves e Moura (2004) ao estudarem os efeitos da aplicação de doses crescentes de biossólido na fertilidade de um Latossolo Vermelho Amarelo, na nutrição mineral e no crescimento de um povoamento de Eucalyptus grandis, observaram que a fertilidade do solo aumentou gradualmente após a aplicação do biossólido, ocorrendo um aumento dos teores de matéria orgânica, nas camadas de 5-10 e 10-20 cm. Brito, Vendrame e Brito (2005) também verificaram incrementos da MOS ao analisarem os efeitos, em médio prazo, da adição de diferentes adubos orgânicos, em especial o esterco bovino, sobre as propriedades químicas de um Latossolo Vermelho escuro distroférrico, do município de
Londrina-PR. Monteiro et al. (2006) ao avaliarem os efeitos da adição de resíduos de madeira nas principais propriedades físicas e químicas dos solos, quando utilizados como cobertura em áreas de reflorestamento, verificaram maior incremento de matéria orgânica através da utilização desses resíduos, contribuindo para o aporte deste material nos solos da região amazônica. Carneiro et al. (2009) verificaram que quanto menor a mobilização e maior a manutenção dos resíduos vegetais sobre o solo, maiores são os teores de carbono orgânico total e de carbono residual ao avaliarem o carbono orgânico total e residual de um Latossolo Vermelho Eutroférrico sob diferentes sistemas de manejo.

A relação de estratificação (RE) pode ser usada para avaliar a qualidade do solo e o funcionamento do ecossistema, permitindo fazer inferencias sobre a influência das práticas de manejo entre as profundidades, ao comparar a camada superficial com as mais profundas. A RE da respiracao basal variou de 0,8 a $1,7(0-5: 5-10 \mathrm{~cm})$ e de 1,0 a 2,0 $(0-5: 10-15 \mathrm{~cm})$ (Figura 4A). Elevadas taxas de estratificação forma observadas nos tratamentos: Húmus, sem NPK, Compostagem laminar + NPK e Húmus + NPK, na camada (0-5:5-10 cm); Na camada (0-5:10-15 cm), as maiores RE aconteceram nos tratamentos Húmus, sem NPK, e Compostagem laminar + NPK. Esses aumentos das relações de estratificação observados na maioria dos tratamentos com manejo mais conservacionista comprovam a sua eficácia em melhorar a atividade microbiana, uma vez que, a presença de resíduos orgânicos, ao proteger o solo dos impactos causados pelo manejo e o pelo clima, também diminui a emissão de $\mathrm{CO}_{2}$ para a atmosfera e aumenta o sequestro de carbono no solo (SILVA; MACHADO, 2000). Porém, esses resultados também comprovam que o maior efeito desse tipo de manejo se concentra mais na camada superficial do solo (SÁ; LAL, 2009). 
Figura 4. Relação de estratificação (0-5:5-10 e 0-5:10-15) da atividade microbiana (A), matéria orgânica do solo (B) e fósforo $(\mathrm{C})$ sob diferentes tratamentos em área de citros no estado de Sergipe.
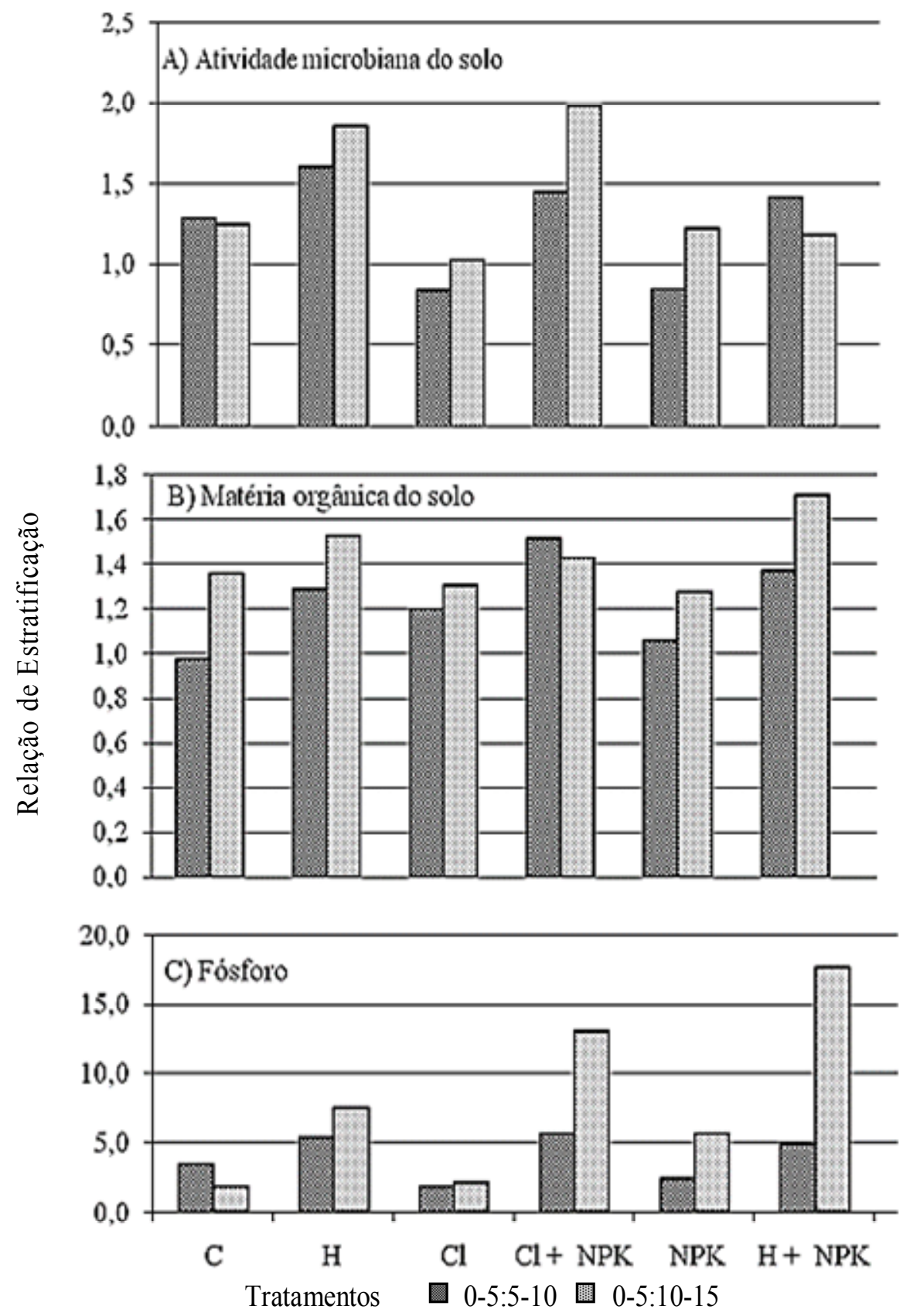

C - Controle sem NPK (projeção da copa mantida livre de plantas invasoras através de capina manual; sem aplicação de fertilizantes); H - Húmus (composto preparado na propriedade agrícola utilizando restos culturais e estercos); CL - Compostagem laminar (resíduos culturais de palha triturada de coqueiro, capim elefante variedade napier, gliricídia e a parte aérea da folha picada do milho dispostos na projeção da copa, em lâminas alternadas com esterco ovino e fosfato de Gafsa até uma altura aproximada de $20 \mathrm{~cm}$ ); CL + NPK - Compostagem laminar + NPK (adubação recomendada pela análise do solo); NPK: Controle com aplicação de NPK; H + NPK - Húmus + NPK.

5. Relação de estratificação (0-5:5-10 e 0-5:10-15) da atividade microbiana (A), matéria orgânica do solo (B) e fósforo (C) sob diferentes tratamentos em área de citros no estado de Sergipe.

Fonte: Elaboração dos autores. 
Para o parâmetro matéria orgânica do solo, a RE variou de 1,0 a 1,5 (0-5:5-10 cm) e de 1,3 a 1,7 (05:10-15 cm) (Figura 4B). Já na primeira estratificação (0-5:5-10 cm), verificou-se um aumento da RE em todos os tratamentos ao serem comparados ao manejo convencional, com e sem NPK, o que comprova a influência dos diferentes tipos de resíduos na camada superficial sobre a camada subsuperficial. Elevadas relações de estratificação da MOS indicam solos preservados, em equilíbrio, com elevada qualidade na camada superficial, e consequentemente que apresentam melhoria nas taxas de infiltração de água, melhor desenvolvimento da macroporosidade para transmissão eficiente do ar e da água através do perfil, maior estabilidade de agregados, suprimento adequado de nutrientes ao longo do tempo e com isso melhor atividade da microbiota (FRANZLUEBBERS, 2002). Podese inferir que, apesar do curto período de tempo (2 anos) em que a área experimental vem sendo mantida sob manejo conservacionista, os resultados ja demonstram efeitos positivos em parametros importantes do solo, quando comparados com o manejo convencional.

Por se tratar de um procedimento de normalização que leva em consideração diferenças inerentes do solo, a RE é um indicador que permite comparar uma grande variedade de solos, em diferentes ambientes. Nesse sentido, Franzluebbers (2002), encontrou RE da matéria orgânica do solo entre 1,1 e 1,9 para solos sob sistema convencional, e de 2,0 a 3,4 em sistemas de manejo conservacionista na Georgia e no Texas. Os resultados de Franzluebbers (2002) corroboram com os nossos em relação as taxas de estratificação da matéria orgânica e da atividade biológica e sugerem que o estoque de matéria orgânica, por si so, nao é um bom indicador de qualidade do solo, mas a estratificação do carbono ativo do solo, como a respiração basal, mostrou maior sensibilidade ao manejo conservacionista.

Quanto aos teores de fósforo, foram encontrados valores considerados elevados para os solos do estado de Sergipe (SOBRAL et al., 2007). Os tratamentos Húmus, Compostagem laminar, Compostagem laminar + NPK, NPK e Húmus + NPK apresentaram valores bem superiores ao considerado alto $(>15)$ nas três profundidades, a exceção do tratamento NPK que teve o teor de $\mathrm{P}$ reduzido ao teor considerado médio ( 7 a 15) na profundidade de 10-15 cm (Tabela 1). O valor da RE variou de 1,8 a 5,6 (0-5:5-10 cm) e de 1,9 a 17,8 (0$5: 10-15 \mathrm{~cm}$ ) (Figura 4C). Na primeira estratificação (0-5:5-10 cm), verificou-se um aumento da RE em todos os tratamentos ao serem comparados ao manejo convencional a exceção dos tratamentos compostagem laminar e NPK (Figura 4C). Na segunda estratificação $(0-5: 10-15 \mathrm{~cm})$, verificou-se aumento da RE em todos os tratamentos em relação ao manejo convencional, sendo alguns deles maiores do que a RE da mata. (Figura 4C). Esse aumento dos teores de $\mathrm{P}$ no solo possivelmente ocorreu devido à adição de resíduos ricos nesse elemento como o esterco e principalmente do fosfato de Gafsa (KIEHL, 1985) que foram incorporados a palha triturada no formato de compostagem laminar, na presença e ausência de minhocas e adubação mineral. A aplicação de resíduos orgânicos em um só local (zona de coroamento) também contribuiu para o elevado teor de P no solo.

\section{Conclusões}

A respiração basal do solo aumentou com a adoção das práticas de manejo conservacionistas, seja através da aplicação de matéria orgânica humificada com NPK seja através de resíduos orgânicos frescos, o que demonstra uma melhoria na atividade microbiológica do solo com consequente benefícios as características do solo e ao desenvolvimento da cultura do citros.

A utilização das taxas de estratificação da respiração basal para avaliar o efeito dos manejos conservacionistas mostrou maior sensibilidade do que a RE da matéria orgânica, indicando que a determinação da matéria orgânica para avaliar os efeitos da qualidade do solo sob diferentes manejos nem sempre é eficiente. 


\section{Referências}

ALEF, K.; NANNIPIERI, P. Methods in applied soil microbiology and biochemistry. London: Academic, $1995.576 \mathrm{p}$.

ANANYEVA, N. D.; SUSYAN, E. A.; CHERNOVA, O. V.; WIRTH, S. Microbial respiration activities of soils from different climatic regions of European Russia. European Journal of Soil Biology, Moscow, v. 44, n. 2, p. 147-157, 2008.

ARAÚJO, A. S. F.; MONTEIRO, R. T. R. Indicadores biológicos de qualidade do solo. Bioscience Journal, Uberlândia, v. 23, n. 3, p. 66-75, 2007.

BORKEN, W.; MUHS, A.; BEESE, F. Application of compost in spruce forest: effects on soil respiration, basal respiration, and microbial biomass. Forest Ecology and Management, Amsterdam, v. 159, n. 1-2, p. 49-58, 2002.

BREVIK, E. C. Soils and climate change: gas fluxes and soil processes. Soil Horizons, North Dakota, v. 53, n. 4, p. 12-23, 2012.

The potential impact of climate change on soil properties and processes and corresponding influence on food security. Agriculture, North Dakota, v. 3, n. 3, p. 398-417, 2013.

BRITO, L. M.; AMARO, A. L.; MOURÃO, I.; COUTINHO, J. Transformação da matéria orgânica e do nitrogênio durante a compostagem da fração sólida do chorume bovino. Revista Brasileira de Ciência do Solo, Viçosa, MG, v. 32, n. 5, p. 1959-1968, 2008.

BRITO, O. R.; VENDRAME, P. R. S.; BRITO, R. M. Alterações das propriedades químicas de um latossolo vermelho distroférrico submetido a tratamentos com resíduos orgânicos. Semina: Ciências Agrárias, Londrina, v. 26, n. 1, p. 33-40, 2005.

CANCELLIER, L. L.; AFFÉRRI, F. S.; ADORIAN, G. C.; RODRIGUES, H. V. M.; MELO, A. V.; PIRES, L. P. M.; CANCELLIER E. L. Adubação orgânica na linha de semeadura no desenvolvimento e produtividade do milho. Semina: Ciências Agrárias, Londrina, v. 32, n. 2, p. 527-540, 2011.

CARNEIRO, C. E. A.; MÉLEN JÚNIOR, N. J.; AZEVEDO, M. C. B.; ANDRADE, E. A.; KOGUISHI, M. S.; DIEHL, R. C.; RICCE, W. S.; PASSARIN, A. L.; VAZ, R. H. M.; STELMASCHUK, T. L. L.; GUIMARÃES, M. F.; RALISCH, R. Efeitos dos sistemas de manejo sobre o carbono orgânico total e carbono residual de um Latossolo Vermelho eutroférrico. Semina: Ciências Agrárias, Londrina, v. 30, n. 1, p. 5-10, 2009.

CHAVES, S. B.; PRANDINI, D. F.; CALDEIRA, M. V. W.; CHAVES, D. M. Influência da aplicação de três concentrações de lodo da indústria têxtil na respiração microbiana em um Cambissolo sob diferentes coberturas florestais. Revista Acadêmica, Curitiba, v. 4, n. 2, p. 5769, 2006.

CHENEBY, D.; BRU, D.; PASCAULT, N.; MARON, P.A.; RANJARD, L.; PHILIPPOT, L. Role of plant residues in determining temporal patterns of the activity, size, and structure of nitrate reducer communities in soil. Applied and Environmental Microbiology, Washington D.C, v. 76, n. 21, p. 7136-7143, 2010.

CINTRA, F. L. D.; PORTELA, J. C.; NOGUEIRA, L. C. Caracterização físíca e hídrica em solos dos Tabuleiros Costeiros no Distrito de Irrigação Platô de Neópolis. Revista Brasileira de Engenharia Agrícola e Ambiental, Campina Grande, v. 8, n. 1, p. 45-50, 2004.

COLEMAN, D. C.; HUNTER, M. D.; HUTTON, J.; POMEROY, S.; SWIFT, L. Soil respiration from four aggrading forested watersheds measured over a quarter century. Forest Ecology and Management, Amsterdam, v. 157, n.1-3, p. 247-253, 2002.

CURIEL YUSTE, J.; BALDOCCHI, D. D.; GERSHENSON, A.; GOLDSTEIN, A.; MISSON, L.; WONG, S. Microbial soil respiration and its dependency on carbon inputs, soil temperature and moisture. Global Change Biology, v. 13, n. 9, p. 2018-2035, 2007.

DING, W.; YU, H.; CAI, Z.; HAN, F.; XU, Z. Responses of soil respiration to $\mathrm{N}$ fertilization in a loamy soil under maize cultivation. Geoderma, Amsterdam, v. 155, n. 3-4, p. 381-389, 2010.

EMPRESA BRASILEIRA DE PESQUISA AGROPECUÁRIA - EMBRAPA. Manual de métodos de análise de solo. Centro Nacional de Pesquisa de Solos. 2. ed. Rio de Janeiro: Centro Nacional de Pesquisa de Solos, 1997. $212 \mathrm{p}$.

EMPRESA DE DESENVOLVIMENTO AGROPECUÁRIO DE SERGIPE - EMDAGRO. Informações Básicas Municipais - Município de Umbaúba. Empresa de desenvolvimento agropecuário de Sergipe. Umbaúba: EMDAGRO, 2008. 28 p.

FERREIRA, D. F. ManualPrograma de análises estatísticas (statistical analysis software) e planejamento de experimentos: SISVAR 5.0 (Build 67). Lavras: DEX/ UFLA, 2003. $66 \mathrm{p}$.

FRANZLUEBBERS, A. J. Soil organic matter stratification ratio as an indicator of soil quality. Soil and Tillage Research, Amsterdam, v. 66, n. 2, p. 95-106, 2002.

FRANZLUEBBERS, A. J.; SCHOEMBERG, H. H.; ENDALE, D. M. Surface-soil responses to paraplowing of long-term no-tillage cropland in the Southern Piedmont 
USA. Soil and Tillage Research, Amsterdam, v. 96, n. 1-2, p. 303-315, 2007.

KIEHL, E. J. Fertilizantes orgânicos. Piracicaba: Editora Agronômica Aeres, 1985. 492 p.

KOERBER, G. R.; HILL, P. W.; EDWARDS-JONES, G.; JONES, D. L. Estimating the component of soil respiration not dependent on living plant roots: Comparison of the indirect y-intercept regression approach and direct bare plot approach. Soil Biology and Biochemistry, Oxford, v. 42, n. 10, p. 1835-1841, 2010.

KUMMER, L.; SCHAFER, R. F.; FERREIRA, A. T. S.; FREITAS, M. P.; PAULA, R. A.; DIONISIO, J. A. Respiração e biomassa microbiana em solos sob diferentes sistemas de uso. Scientia Agraria, Curitiba, v. 9, n. 4, p. 559-563, 2008.

LAL, R. Managing soils and ecosystems for mitigating anthropogenic arbon emissions and advancing global food security. BioScience, Washington, v. 60, n. 9, p. 708-721, 2010.

MAZURANA, M.; FINK, J. R.; CAMARGO, E.; SCHNITT, R. A.; CAMARGO, F. A. O. Estoque de carbono e atividade microbiana em sistema de plantio direto consolidado no Sul do Brasil. Revista de Ciências Agrárias, Lisboa, v. 36, n. 3, p. 288-296, 2013.

MENDONÇA, E. S.; MATOS, E. S. Matéria orgânica do solo: métodos de análises. Viçosa: UFV, 2005. 107 p.

MODESTO, P. T.; SCABORA, M. H.; COLODRO, G.; MALTONI, K. L.; CASSIOLATO, A. M. R. Alterações em algumas propriedades de um latossolo degradado com uso de lodo de esgoto e resíduos orgânicos. Revista Brasileira de Ciência do Solo, Viçosa, MG, v. 33, n. 5, p. 1489-1498, 2009.

MONTEIRO, K. F. G.; KERN, D. C.; RODRIGUES, T. E.; RUIVO, M. L. P.; FARIAS, P. R. S. Caracterização dos argissolos amarelos com adição de resíduos de madeira: uma alternativa de uso como cobertura em solos da Amazônia paraense. Boletim do Museu Paraense Emílio Goeldi. Ciências Naturais, Belém, v. 1, n. 1, p. 139-148, 2006.

NUNES, M. U. C.; SANTOS, J. R. Alternativas tecnológicas para o aproveitamento de resíduos de coqueiro gigante para produção de adubo orgânico; compostagem e outras. In: CINTRA, F. L. D, FONTES, H. R.; PASSOS, E. E. M.; FERREIRA, J. M. S. Fundamentos tecnológicos para revitalização das áreas cultivadas com coqueiro gigante no Nordeste do Brasil. Aracaju: Embrapa Tabuleiros, 2009. p. 127-144.

PARKIN, T. B.; DORAN, J. W.; FRANCOP-VIZCAIINO, E. Field and laboratory tests of soil respiration. In: DORAN, J. W.; JONES, A. (Ed.). Methods for assessing soil quality. Madison: Soil Science Society of America, 1996. p. 231-245.

PAVINATO, P. S.; ROSOLEM, C. A. Disponibilidade de nutrientes no solo: decomposição e liberação de compostos orgânicos de resíduos vegetais. Revista Brasileira de Ciência do Solo, Viçosa, MG, v. 32, n. 3, p. 911-920, 2008.

POWLSON, D. S. Manejo da matéria orgânica de solos. In: MACHADO, P. L. O. A. O papel dos microrganismos na conservação da matéria orgânica dos solos tropicais. Rio de Janeiro: Embrapa Solos, 2001. p. 7-9. (Documentos, v. 24).

PRAGANA, R. B.; NOBREGA, R. S. A.; RIBEIRO, M. R.; LUSTOSA FILHO, J. F. Atributos biológicos e dinâmica da matéria orgânica em Latossolos Amarelos na região do Cerrado piauiense sob sistema plantio direto. Revista Brasileira de Ciência do Solo, Viçosa, MG, v. 36, n. 3, p. 851-858, 2012.

ROCHA, G. N.; GONCALVES, J. L. M.; MOURA, I. M. Mudanças da fertilidade do solo e crescimento de um povoamento de Eucalyptus grandis fertilizado com biossólido. Revista Brasileira de Ciência do Solo, Viçosa, MG, v. 28, n. 4, p. 623-639, 2004.

RODDA, M. R. C.; CANELLAS, L. P.; FAÇANHA, A. R.; ZANDONADI, D. B.; GUERRA, J. G. M.; ALMEIDA, D. L.; SANTOS, G. A. Estímulo no crescimento e na hidrólise de ATP em raízes de alface tratadas com humatos de vermicomposto: II - efeito da fonte de vermicomposto. Revista Brasileira de Ciência do Solo, Viçosa, MG, v. 30, n. 4, p. 657-664, 2006.

SÁ, J. C. M.; LAL, R. Stratification ratio of soil organic matter pools as an indicator of carbon sequestration in a tillage chronosequence on a Brazilian Oxisol. Soil and Tillage Research, Amsterdam, v. 103, n. 4, p. 46-56, 2009.

SAMPAIO, D. B.; ARAÚJO, A. S. F.; SANTOS, V. B. Avaliação de indicadores biológicos de qualidade do solo sob sistemas de cultivo convencional e orgânico de frutas. Ciência e Agrotecnologia, Lavras, v. 32, n. 2, p. 353-359, 2008.

SCHMIDT, R. O.; SANA, R. S.; LEAL, F. K.; ANDREAZZA, R.; CAMARGO, F. A. O.; MEURER, E. J. Biomassa e atividade microbiana do solo em sistemas de produção olerícola orgânica e convencional. Ciência Rural, Santa Maria, v. 43, n. 2, p. 270-276, 2013.

SHARMA, S. B.; SAYYED, R. Z.; TRIVEDI, M. H.; GOBI, T. A. Phosphate solubilizing microbes: sustainable approach for managing phosphorus deficiency in agricultural soils. Singer Plus, Gujarat v. 2, n. 1, p. 587599, 2013. 
SILVA, C. A.; MACHADO, P. L. O. A. Sequestro e emissão de carbono em ecossistemas agrícolas: estratégias para o aumento dos estoques de matéria orgânica em solos tropicais. Rio de Janeiro: Embrapa Solos, 2000. 23 p. (Documentos, v. 19).

SILVA, R. R.; SILVA, M. L. N.; CARDOSO, E. L.; MOREIRA, F. M. S.; CURI, N.; ALOVISI, A. M. T. Biomassa e atividade microbiana em solo sob diferentes sistemas de manejo na região fisiográfica campos das Vertentes - MG. Revista Brasileira de Ciência do Solo, Viçosa, MG, v. 34, n. 5, p. 1585-1592, 2010.

SILVEIRA, M.; CASTILHOS, D. D.; CASTILHOS, R. M. V.; VIVIAN, G. Biomassa e atividade microbiana em solo acrescido de dejeto suíno. Revista Brasileira de Agrociência, Jaboticabal, v. 17, n. 1, p. 85-93, 2011.

SOBRAL, L. F.; VIÉGAS, P. R. A.; SIQUEIRA, O. J. W.; ANJOS, J. L.; BARRETO, M. C. V.; GOMES, J. B. V. Recomendações para o uso de corretivos e fertilizantes no estado de Sergipe. Aracaju: Embrapa Tabuleiros Costeiros, 2007. $251 \mathrm{p}$.

TANG, X.; LIU, S.; ZHOU, G.; ZHANG, D.; ZHOU, C. Soil atmoshpheric exchange of $\mathrm{CO}_{2}, \mathrm{CH}_{4}$, and $\mathrm{N}_{2} \mathrm{O}$ efflux in three subtropical forest ecosystems in southern China. Global Change Biology, v. 12, n. 3, p. 546-560, 2006.

TEDESCO, M. J.; SELBACH, P. A.; GIANELLO, C.; CAMARGO, F. A. O. Resíduos orgânicos no solo e impactos no ambiente. In: SANTOS, G. A.; CAMARGO, F. A. O. (Ed.). Fundamentos da matéria orgânica do solo. Porto Alegre: Gêneses, 1999. p. 159-192.
TRANNIN, I. C. B.; SIQUEIRA, J. O.; MOREIRA, F. M. S. Características biológicas do solo indicadoras de qualidade após dois anos de aplicação de biossólido industrial e cultivo de milho. Revista Brasileira de Ciência do Solo, Viçosa, MG, v. 31, n. 5, p. 1173-1184, 2007.

VIEIRA, G. D.; CASTILHOS, D. D.; CASTILHOS, R. M. V. Atributos microbianos do solo após a adição de lodo anaeróbio da estação de tratamento de efluentes de parboilização do arroz. Revista Brasileira de Ciência do Solo, Viçosa, MG, v. 35, n. 2, p. 543-550, 2011.

YEOMANS, J. C.; BREMNER, J. M. A. Rapid and precise method for routine determination of organic carbon in soil. Communications in Soil Science and Plant Analysis, New York, v. 19, n. 13, p. 1467-1476, 1988.

YI, Z.; FU, S.; YI, W.; ZHOU, G.; MO, J.; ZHANG, D.; DING, M.; WANG, X.; ZHOU, L. Partitioning soil respiration of subtropical forests with different successional stages in south China. Forest Ecology and Management, Amsterdam, v. 243, n. 2-3, p. 178-186, 2007.

ZATORRE, N. P. Atributos biológicos do solo como indicadores de qualidade do solo. Gaia Scientia, Seropédica, v. 2, n. 6, p. 9-13, 2008.

ZIMMERMANN, S.; FREY, B. Soil respiration and microbial properties in an acid forest soil: effects of wood ash. Soil Biology and Biochemistry, Oxford, v. 34, n. 11, p. 1727-1737, 2002. 
